\title{
Pour Éric Chevillard, ouvrage dirigé par Pierre Bayard
}

\section{Gianmaria Finardi}

\section{Q OpenEdition \\ 1 Journals}

\section{Edizione digitale}

URL: http://journals.openedition.org/studifrancesi/1632

DOI: 10.4000/studifrancesi. 1632

ISSN: 2421-5856

\section{Editore}

Rosenberg \& Sellier

\section{Edizione cartacea}

Data di pubblicazione: 1 novembre 2014

Paginazione: 639-640

ISSN: 0039-2944

\section{Notizia bibliografica digitale}

Gianmaria Finardi, « Pour Éric Chevillard, ouvrage dirigé par Pierre Bayard», Studi Francesi [Online], 174 (LVIII | III) | 2014, online dal 01 novembre 2014, consultato il 18 septembre 2020. URL : http:// journals.openedition.org/studifrancesi/1632; DOI : https://doi.org/10.4000/studifrancesi.1632

Questo documento è stato generato automaticamente il 18 settembre 2020.

\section{(c) (i) (9)}

Studi Francesi è distribuita con Licenza Creative Commons Attribuzione - Non commerciale - Non opere derivate 4.0 Internazionale. 


\title{
Pour Éric Chevillard, ouvrage dirigé par Pierre Bayard
}

\author{
Gianmaria Finardi
}

\section{NOTIZIA}

Pour Éric Chevillard, ouvrage dirigé par Pierre BAYARD, Paris, Minuit, 2014, pp. 128.

1 In questa miscellanea quattro illustri critici letterari cercano di definire l'opera di Éric Chevillard, che si vuole refrattaria a qualsivoglia tentativo di classificazione. Nell'intervento inaugurale, L'Herméneutique du fou (pp. 7-36), Bruno BLANCKEMANN si interroga sulle implicazioni del polimorfismo di una scrittura che induce a interpretazioni destinate ad apparire riduttive, quando non deliranti. Lo studioso esamina due testi situati agli antipodi della produzione, così da registrare le costanti $\mathrm{e}$ le evoluzioni di un intero percorso letterario: questo è il caso della finzione dell'esordio, Mourir m'enrhume (1987), che mette in scena la vicenda minimale di un agonizzante, e del romanzo più recente, L'Auteur et moi (2013), dove un autore finisce per competere con se stesso, ingaggiando una controversia con il narratore del proprio racconto.

2 Nella prima opera, la proteiformità testuale si esprime attraverso la narrazione di un individuo che non cessa di morire, grazie a un'energia vitale che a ogni capitolo si rinnova con un frammento di scena, di dialogo, o offrendo uno scorcio di coscienza introspettiva; nell'ultima, è la moltiplicazione delle rappresentazioni testuali dell'autore a trascinare il lettore nella ricerca senza fine di un senso. Il logos si rivela, quindi, il bersaglio ultimo e comune a tutti i testi dell'ironia di Chevillard, che si produce nella perturbazione della lingua per mimarne e minarne il rapporto di subordinazione referenziale.

3 Nel secondo saggio, Rendre bête (pp. 37-58), Tiphaine SAMOYAULT indaga le ragioni dello smarrimento del lettore: egli diviene vittima di innumerevoli giochi di specchi, tesi a impedirgli di assumere qualsivoglia posizione stabile all'interno dei testi. La bestialità 
di cui si crede responsabile il lettore, a uno sguardo più attento, è imputabile alle posture bestiali letteralmente occupate da Chevillard.

Non a caso, per dichiarare la sua ispirazione antirealista l'autore ricorre a un bestiario fantaisiste: sceglie gli esseri meno referenziali possibili, li pseudonimizza, trasformandoli in pseudo-animali, oppure li va a pescare in un immaginario immediatamente poetico; più spesso, alla maniera di Roubaud, li chiama in causa solo per il nome, inscrivendoli in un sistema di segni che mette a dura prova la logica e il senso. Animalizzando anche il linguaggio, allora, Chevillard abolisce le normali distinzioni ontologiche, così da estendere il territorio del possibile al di là del reale.

Nel terzo contributo, Littérature spéculative (pp. 59-92), Dominique VIART va alla ricerca di un'etichetta in grado di ovviare al problema dell'endemica fuggevolezza dell'opera: lo studioso ricorre alla categoria della bathmologie, coniata da Barthes per descrivere una sorta di nuova scienza, per cui ogni discorso viene trasportato nelle elucubrazioni della lingua. In tal modo, Viart isola il duplice movimento che anima la scrittura. Da una parte, Chevillard opera il rovesciamento di qualsivoglia posizione, minandone la certezza con l'aiuto di puntuali interventi metaletterari; il lettore viene immancabilmente spiazzato dal testo, che mira a smontare le sue idee preconcette per rivendicare la propria originalità. Il carattere speculare delle opere, d'altra parte, risulta inscindibile da quello speculativo, poiché i testi si danno come terreno di esercizio nel quale perturbare le forme letterarie codificate.

In una tale moltiplicazione delle vie di fuga finzionali la sola postura plausibile tenuta da Chevillard è quella del contestatore che si avvale di una ferrea logica enunciativa per sovvertire il modo di intendere il mondo. L'autore, infatti, non si accontenta di demolire il sistema in vigore dall'interno, decostruendo gli automatismi del linguaggio, ma cerca di testare la solidità della propria visione, per inverosimile che essa possa risultare. È un'inquietudine esistenziale, del resto, ad alimentare questa scrittura paradigmatica, anche se essa conserva l'aspetto giubilatorio di un gioco di sostituzioni e rovesciamenti.

7 Nell'intervento conclusivo, Pour une nouvelle littérature comparée (pp. 93-118), Pierre BAYARD si prefigge di dimostrare come il romanzo chevillardiano possa aiutare a rinnovare profondamente il modo di accostarsi a autori e testi. Bisogna innanzitutto considerare l'opera come emblema della singolarità: mentre la natura e il comportamento paradossale degli attanti esula dalle tradizionali categorie, ancora più atipica è la loro visione del mondo. È quindi chiaro, come testimoniano tra l'altro le numerose mises en abyme, che il vero oggetto di questi romanzi è la difficoltà della scrittura a dire il reale conservando la propria originalità. Di qui, la lingua balbuziente di Chevillard che, se non risulta sempre autocontraddittoria, ricorre alle figure di un'analogia paradossale; solo evitando di mettere in relazione termini troppo vicini sul piano semantico, ossia procedendo per comparaisons éloignantes, l'autore di Au plafond può sperare di cogliere la realtà, senza privarla della sua specificità. Proprio esaltando questo principio della differenza, lo scarto che misura l'allargamento e l'arricchimento del campo della coscienza, è possibile uscire da una concezione arcaica della comparatistica: occorre privilegiare la diversità esistente tra autori e testi molto distanti, per restituirle il valore di un autentico processo creativo. 